\title{
VEINTICINCO AÑOS DE LIDERAZGO PRESIDENCIAL
}

\author{
ANTONIOTORRES DEL MORAL
}

Catedrático de Derecho Constitucional UNED 


\section{SUMARIO}

1. Caracterización del Gobierno español. 2. Un Gobierno fácil de consTRUIR Y DIFICIL DE REMOVER. 3. LIDERAZGO DEL PRESIDENTE VERSUS COLEGIALIDAD DEL Gobierno. 4. LIDERAZGO Y COLEGIALIDAd EN EL MODELO ESPAÑOL DE RESPONSABILIDAD POLITICA DEL GOBIERNO. 5. LIDERAZGOY COLEGIALIDAD EN LA PRÁCTICA POLÍTICA. 5.1. Gobierno de liderazgo presidencial pleno (II, III, IV y VII Legislaturas). 5.2. Gobierno de liderazgo menos pleno (V y VI Legislaturas). 5.3. Gobierno de liderazgo decreciente (1979-1981). 5.4. Gobierno sin liderazgo (1981-1982). 6. CONCLUSIÓN: LA COLEGIALIDAD COMO PRODUCTO DEL LIDERAZGO. 7. LIDERAZGO O COLEGIALIDAD DEL GOBIERNO DE LAS COMUNIDADES AUTÓNOMAS. 


\title{
VEINTICINCO AÑOS DE LIDERAZGO PRESIDENCIAL
}

\author{
POR \\ ANTONIOTORRES DEL MORAL \\ Catedrático de Derecho Constitucional \\ UNED
}

\section{CARACTERIZACIÓN DEL GOBIERNO ESPAÑOL}

Cuando el artículo $1 .^{\circ}-3$ de la Constitución española dice que la forma política del Estado español es la monarquía parlamentaria, está haciendo dos afirmaciones a un tiempo: 1) que la forma de la Jefatura del Estado es monárquica; y 2) que el sistema de gobierno es parlamentario. Los otros caracteres que perfilan el Estado español (democrático y autonómico) están, uno, explícitamente reflejado en el artículo $1 .^{\circ}-1$, y el otro, en el artículo $2 .^{\circ}$ Los cuatro, además, están ampliamente desarrollados en el resto del articulado.

Las variantes del sistema parlamentario son muchas, a veces con acusadas diferencias, pero conservando siempre el aire de familia. Su elemento esencial es la relación fiduciaria existente entre el Gobierno y el Parlamento, absolutamente necesaria para el sostenimiento de aquél, aunque no siempre para su formación e inicio de su actividad; su contrapeso, igualmente ineludible, es la solubilidad del Parlamento por el Gobierno.

El sistema de gobierno constitucionalmente establecido en España responde a la anterior y sumaria descripción. Pero todavía hemos 
de hacer algunas precisiones antes de plantearnos el objeto principal de este trabajo.

Como es sabido, la evolución "natural» del sistema parlamentario en el siglo $X X$ y en lo que va de $X X I$ es la que ha llevado al denominado Gobierno de Canciller, de Premier o de Primer Ministro, en el que la figura preponderante es la de éste, de manera que deja de ser un primero entre iguales, como acaso lo fue en el régimen liberal clásico, y pasa a ser un verdadero Jefe del Gobierno, con entidad política y naturaleza jurídica diferente a las del resto de los miembros del Ejecutivo. Los ejemplos de Alemania y del Reino Unido son bien elocuentes. En cambio, Francia responde a otro esquema.

¿Se ha alineado la Constitución española con esa corriente. A mi juicio, los rasgos del sistema de gobierno español son:

1. Un Gobierno fácil de construir y difícil de remover.

2. Un Gobierno que, en principio, responde más al modelo de liderazgo del Presidente que al de colegialidad.

Es lo que tratamos de justificar en las páginas que siguen.

\section{UN GOBIERNO FÁCIL DE CONSTRUIR Y DIFÍCIL DE REMOVER}

En la circunstancia política española de 1978 quizá era importante la constitucionalización del sistema electoral del Congreso. La izquierda hizo bandera de ello sin poner en cuestión en ningún momento que ese sistema debía ser el proporcional. La derecha defendió el sistema de mayoría, como antes, con ocasión de la Ley para la Reforma Política lo había hecho - infructcuosamente - lo más granado del franquismo, pero después se plegó a la constitucionalización del sistema proporcional. Con este sistema se habían celebrado las elecciones de 1977, con resultados globalmente satisfactorios y parecía incuestionable seguir contando con un sistema electoral que había permitido la conformación del Congreso con un pluralimo limitado, subrayando los dos términos.

El sistema, mal que bien, ha funcionado durante veinticinco años, con la añadidura de que se ha adoptado también, en sus ras- 
gos generales y mudando lo mudable, para las demás elecciones (municipales, autonómicas y europeas). Ello nos ha deparado un Congreso de los Diputados cuya representatividad nadie discute de forma solvente; es discutido por algunos, pero insisto: no de forma solvente.

Porque en una democracia representativa siempre hay algo más que el mero ajuste decimal entre votos y escaños. Ante todo y sobre todo, la aparición del Gobierno en escena y su actual prevalencia sobre el Parlamento en el funcionamiento del sistema político. Hoy, una elección parlamentaria no es sólo parlamentaria, sino también, y muy principalmente, gubernamental. Salvo en ciertos países de multipartidismo atomizado, el resultado electoral puede y debe interpretarse como el mandato que hace el electorado de una determinada conformación del Gobierno.

Al sistema electoral se le puede demandar, por tanto, no sólo que facilite la formación de un Parlamento deliberante y controlador, sino también la de un Gobierno que dirija la política y desarrolle un programa que haya recibido un consistente respaldo popular. Desde esta perspectiva, no son repudiables ciertos elementos correctores del sistema electoral proporcional español que pretenden (así lo decía la propia Ley para la Reforma Política) evitar un excesivo fraccionamiento de la Cámara y facilitar la formación del Gobierno. Por eso, quienes idearon el sistema electoral español, con su prima fuerte al partido ganador, cantaban este rasgo como una de sus virtudes.

Así, pues, la legislación electoral puso las condiciones, como está empíricamente demostrado, para que hubiera cuatro grandes partidos de ámbito nacional, de los cuales dos (los más centrados) aventajarían a los otros dos (que ulteriormente quedaría sólo en uno que se extiende desde el centro hasta la derecha), y que habría además sendos partidos nacionalistas fuertes en el País Vasco y en Cataluña. Después ha habido algunas variaciones, pero el sistema apuntaba a lo antes referido.

Las diferencias entre los dos grandes partidos nacionales y los otros dos fueron notables en 1977 y en 1979. UCD logró una prima de escaños considerable, pudiendo gobernar con un $35 \%$ de votos. Una sobrerrepresentación importante, pero menor, obtuvo el PSOE (después se cambiaron las tornas a partir de 1982). En cambio, los dos partidos nacionales menores fueron fuertemente "penalizados". Por eso, cuando las Cortes constituyentes abordaron la tarea de delinear los elementos del sistema electoral para el Congreso de los Diputados, no podía esperarse gran divergencia de lo existente. 
Como asi fue: el artículo 68 de la Constitución vino a dejar intacto y a consagrar al máximo nivel normativo el sistema expuesto (que provenía de la Ley para la Reforma Política y el Decreto-Ley Electoral de 18-III-1977). De entonces acá ése ha sido el sistema electoral vigente, con su mencionado efecto en orden a la facilidad de formar Gobierno. La Ley Orgánica Electoral de 1985 no hizo sino desarrollar esta normativa.

Además, el artículo 99 de la Constitución, si bien exige una mayoría absoluta de diputados para obtener la investidura, en una segunda votación, dos días más tarde valida para el mismo efecto la mayoría simple. Con eso y con los beneficios del sistema electoral antes enunciados, no es difícil encontrar una "fórmula" de Gobierno que pueda ofrecer el candidato para obtener la investidura?.

La formulación de este primer epígrafe demanda que hagamos parecidas consideraciones acerca de la dificultad de remover al Gobierno. Pero hay en este número de la Revista un estudio sobre este extremo, sin que deba yo decir nada sobre el particular que no sea la dificultad de aprobación de una moción de censura por parte del Congreso de los Diputados y la facilidad, por parte del Gobierno, de ganar una cuestión de confianza. Más adelante me extenderé un poco más al hablar del modelo de responsabilidad política. En todo lo demás remito a dicho trabajo ${ }^{2}$.

\section{LIDERAZGO DEL PRESIDENTE VERSUS COLEGIALIDAD DEL GOBIERNO}

Discutió la doctrina durante los primeros años de vigencia constitucional si nuestra norma fundamental se había inclinado más por un Gobierno colegial o por uno liderado por su Presidente. Actualmente hay acuerdo unánime, o casi, acerca de la primacia del principio de liderazgo respecto del de colegialidad. Pero es preciso comprobarlo.

El artículo 98 de la Constitución destaca el liderazgo del Presidente del Gobierno por cuanto le confiere la dirección de la acción gubernamental y la coordinación de las funciones de los demás miemmo número.

1 Cfr. el artículo "Veinticinco años de formación del Gobierno" en este mis-

2 Cfr. el artículo «Veinticinco años de relación fiduciaria entre las Cortes y el Gobierno» en este mismo número. 
bros del Gobierno. $Y$ otros preceptos parecen corroborar la misma impresión. Destaquemos, entre otros, los siguientes rasgos que así lo confirman:

a) Es el Presidente, no el Gobierno, el que recibe la investidura del Congreso de los Diputados, según regula el artículo 99.

b) Es el Presidente el que puede plantear una cuestión de confianza ante el Congreso, según dispone el artículo 112, pues la participación del Gobierno a este respecto se reduce a deliberar previamente en Consejo de Ministros, pero sin condicionamiento alguno de la decisión del Presidente.

c) Es igualmente el Presidente el que, conforme al artículo 115.1, propone al Rey (lo que, en términos operativos, pero, al mismo tiempo, exquisitamente jurídicos, significa decidir) la disolución del Congreso, del Senado o de las Cortes Generales, con la correspondiente convocatoria de elecciones. En esta ocasión, el texto constitucional es más explícito aún (acaso innecesariamente rotundo), puesto que, aunque dispone el cumplimiento del mismo requisito formal (la previa deliberación del Consejo de Ministros), se cuida de añadir que el Presidente actúa «bajo su exclusiva responsabilidad».

d) Es el Presidente quien, según los artículos 62.e y 100, propone (esto es, decide) el nombramiento y separación de los demás miembros del Gobierno por parte del Rey, con lo que parece que, en principio (subrayemos de momento las dos expresiones: parece y en principio), éstos dependen de la exclusiva confianza de aquél, y no también del Rey, como sucedia en la monarquía limitada.

Podríamos continuar pero creo que con lo expuesto es suficiente para sostener la tesis de la primacía del liderazgo. El resto del funcionamiento del Gobierno no es sino corolario lógico de lo anteriormente reflejado:

1. Los ministros han de cumplir el programa del Presidente, bien el que defendió ante el Congreso de los Diputados para recibir la investidura, bien, en su caso, el rectificado al plantearle al mismo Congreso una cuestión de confianza.

2. Los ministros han de seguir, por tanto, las instrucciones del Presidente $y$, a la vez, tenerle informado de la gestión de sus correspondientes departamentos ministeriales, pudiendo el Presidente intervenir en dicha gestión e incluso recabar para 
sí cualquier cometido de la misma. El ejemplo más notorio es el de la política internacional, pero ya se supone que no es el único.

A la vista de la anterior exposición, podemos concluir, en principio (insistamos de nuevo en la cautela) que la Constitución española responde a la evolución aludida al comienzo de estas páginas, conforme a la cual el sistema parlamentario había desembocado en Gobierno de Canciller, de Premier o de Primer Ministro. Incluso, como destacó tempranamente Garrido Falla, el Presidente del Gobierno español es uno de los que tiene más poderes en comparación con sus homólogos de otros paises.

La Ley del Gobierno, de 1997, parece confirmar este enfoque cuando en su artículo $2 .^{\circ}$ relaciona las facultades concretas del Presidente, reiterando preceptos constitucionales, pero añadiendo de forma harto significativa que le corresponde:

- Representar al Gobierno.

- Establecer el programa político de éste.

- Dirigir la política de defensa.

- Convocar, presidir y fijar el orden del día en las reuniones del Consejo de Ministros, salvo cuando lo preside el Rey.

- Crear, modificar y suprimir los Departamentos ministeriales. y las Secretarias de Estado, asi como aprobar la estructura orgánica de la Presidencia del Gobierno.

- Resolver los conflictos de atribuciones surgidos entre los diferentes Ministerios; etcétera.

Ahora bien, no está ayuna de argumentos la posición contraria - hoy claramente en minoría - que pone el acento en el principio de colegialidad. Pues, efectivamente, el ordenamiento jurídico destaca este aspecto en otras tantas ocasiones. Así, por ejemplo:

a) Con carácter general, el artículo 97 de la Constitución identifica al Gobierno como el órgano de dirección de la política interior y exterior, de la dirección de la Administración civil y militar y de la defensa del Estado, así como el que ejerce la función ejecutiva y la potestad reglamentaria.

b) Ya hemos visto que la Constitución requiere la previa deliberación del Consejo de Ministros para la adopción de determinadas decisiones. 
c) El artículo 134.1 le atribuye la elaboración de los Presupuestos Generales del Estado y el artículo 131.2 la de los proyectos de planificación general de la economía.

d) El artículo 87.1 lo identifica, junto con el Congreso y el Senado, como los órganos dotados de iniciativa legislativa.

e) El artículo 86.1 le atribuye la potestad de dictar decretosleyes y el artículo 82 dispone la posible delegación de las Cortes en el Gobierno de la potestad de dictar normas con rango de ley (decretos legislativos).

f) Puede requerir al Tribunal Constitucional para que declare si existe o no contradicción entre el texto de un tratado internacional, antes de ser ratificado, y la Constitución; etcétera.

Estas funciones se extienden al ejercicio de ciertas prerrogativas regias, a su participación en la designación de dos miembros del Tribunal Constitucional, a las relaciones internacionales y a las de los poderes centrales con los de las Comunidades Autónomas. En la importancia de todas estas funciones vieron algunos autores, como $\mathrm{G}$. Peces-Barba, un cierto equilibrio entre liderazgo y colegialidad o incluso una cierta preeminencia de ésta. Y la Ley del Gobierno subraya su importancia al decir que le corresponde, entre otras facultades, la de acordar la negociación y firma de los tratados internacionales, disponer la emisión de Deuda Pública...

No obstante, puede redargüirse en beneficio del principio de liderazgo que el programa del Gobierno es único, el del Presidente, y los demás miembros deben su cargo y permanencia en él a la discrecional confianza de éste. De manera que, incluso en el ejercicio de sus competencias colegiales, el Gobierno está dirigido por su Presidente.

\section{LIDERAZGOY COLEGIALIDAD EN EL MODELO ESPAÑOL DE RESPONSABILIDAD POLITICA DEL GOBIERNO}

Si incorporamos a nuestro análisis el modelo de responsabilidad política regulada en la Constitución y en el Reglamento del Congreso, la cuestión adquiere un matiz digno de reseña.

Recordemos que la Constitución dice en su artículo 108 que el Gobierno responde solidariamente ante el Congreso de los Diputados. Talmodelo de responsabilidad subraya la colegialidad del Gobierno, pero ¿lo hace frente al liderazgo del Presidente?; ¿quiere decir que, en 
punto a la responsabilidad política del Gobierno y a la correspondiente y eventual remoción de los titulares de cargos gubernamentales, el Presidente es uno más y que une su suerte a la del Gobierno en este unidireccional sentido? Más bien sucede lo contrario: la cohesión y colegialidad enfatizada por el modelo de responsabilidad solidaria no sólo no desdice el liderazgo del Presidete, sino que lo refuerza, como se pone de manifiesto al examinar los institutos concretos en los que se dilucida dicha responsabilidad:

a) Recordemos que es el Presidente, no el Gobierno, quien somete voluntariamente al Congreso la responsabilidad política solidaria y, por tanto, la del Gobierno todo entero.

b) La moción de censura es presentada en el Congreso contra el Gobierno en bloque, pero luego se sustancia entre el Presidente en ejercicio y el candidato alternativo propuesto, pues no en vano nuestra Constitución combina la censura y la investidura extraordinaria en un solo procedimiento.

c) En uno y otro caso, perdida la confianza de la Cámara, la dimisión obligatoria es presentada por el Gobierno, no por el Presidente, según establece el artículo 114. Aun así, el resultado sería el mismo que si la dimisión la presentara el Presidente, pues una de las causas de cese del Gobierno es precisamente la dimisión del Presidente (y su muerte), como explicita el artículo 101.1. Aún no se ha dado la circunstancia, pero, en caso de darse, lo normal será que el Presidente, como representante del Gobierno, presente la dimisión de éste como un todo.

En todo caso, podemos interpretar que el primer instituto (la cuestión de confianza) subraya más el liderazgo del Presidente, y el segundo (la moción de censura), el contrario. Pero incluso ateniéndonos a ésta y a la dimisión colegiada, el resultado es menos diáfano de lo sugerido por la literalidad constitucional; y eso por varias razones. En primer lugar, todos los demás miembros del Gobierno deben su cargo y su permanencia en él al Presidente, en tanto éste no se lo debe a ningún supuesto e irreal Gobierno que le preexista. En segundo término, y como consecuencia de lo anterior, todos los demás miembros del Gobierno son políticamente responsables ante el Presidente, pero éste no responde ante el Gobierno. Por último, la moción de censura se dirige contra el Gobierno, según la literalidad del artículo 113.1 de la Constitución, pero el Gobierno es censurado por ejecutar la política del Presidente, por lo que tal precepto constitucional ha de ser rein- 
terpretado sistemáticamente de modo mucho más alineado con el principio de liderazgo presidencial.

La conclusión es derecha: cuando se habla de colegialidad, se trata de una colegialidad dirigida por el Presidente y no opuesta - ni siquiera dialécticamente- a éste.

Exagerando un tanto la nota, podemos decir que hoy, en España, la función ejecutiva y de gobierno es ejercida por el Presidente, el cual confía competencias a los ministros; la función legislativa es iniciada por el Gobierno y, por tanto, bajo la dirección del Presidente; y la función de control que corresponde a la minoría, a la Oposición, es controlada por la mayoría, o, lo que es igual, por el Gobierno, lo que quiere decir por su Presidente en última instancia. Él es el árbitro del juego político. El problema de la democracia española reside en que el árbitro no se conduzca arbitrariamente.

\section{LIDERAZGOY COLEGIALIDAD EN LA PRÁCTICA POLÍTICA}

En conclusión, parece tener más fuerza el principio de liderazgo que el de colegialidad. Pero esta tesis ha de sufrir el contraste con la realidad política en una democracia de partidos como la española. $Y$ la experiencia habida hasta ahora abona la tesis de que la posición del Presidente respecto del Gobierno está muy afectada por los demás datos de esa realidad política.

El liderazgo se ve notablemente reforzado cuando en la praxis política se dan los siguientes elementos:

1. Mayoria absoluta de un partido gobernante en el Congreso de los Diputados (que suele ir acompañada de una mayoría aún más reforzada en el Senado; este último dato es secundario, pero no totalmente irrelevante, sobre todo por la práctica torticera que se ha introducido en esta Cámara durante la última legislatura) ${ }^{3}$.

2. Liderazgo no discutido del Presidente del Gobierno en dicho partido.

3. Partido gobernante muy cohesionado o, por lo menos, sin fisuras importantes.

3 Cfr. mi trabajo en este número "Veinticinco años de Senado». 
Pero esta posición predominante del liderazgo cede enteros según van faltando alguno o algunos de los mencionados elementos. $Y$, cuando faltan todos, no hay liderazgo ni colegialidad; en realidad, no hay Gobierno, aunque siga figurando uno, y a su cabeza un Presidente. Veámoslo.

\subsection{Gobierno de liderazgo presidencial pleno (II, III, IV y VII Legislaturas)}

La constelación de factores antes enunciada se dio en las legislaturas II a IV y se da actualmente en la VII, si bien en la IV el Gobierno estaba asentado tan sólo en el $50 \%$ de los escaños del Congreso. En la II Legislatura se produjo un vuelco en el sistema de partidos y un cambio en el Gobierno, que pasó a ocupar el PSOE, desapareciendo el partido hasta entonces gobernante (UCD) y bajando ostensiblemente el Partido Comunista, que ni siquiera pudo formar grupo parlamentario, quedando sólo en cuatro escaños. Por el contrario, Alianza Popular se vio relanzada, recogiendo los votos conservadores de UCD, lo mismo que el PSOE había recogido los demás de este mismo partido.

El subsistema nacional de partidos parecía aclararse por la disminución de su número con presencia parlamentaria y su perfil más bipartidista, aunque bastante desequilibrado a favor del partido gobernante, que además tenía también las riendas del poder municipal y de la mayoría de las Comunidades Autónomas. Disponía, pues, el partido del Gobierno de un inmenso poder, que lo cohesionó internamente y lo disciplinó más de lo que ya lo estaba.

Se dieron cita, pues, las tres condiciones apuntadas, alguna de ellas incluso con sobreabundancia (202 escaños), y el Gobierno funcionó como séquito de su Presidente, sin discordancias reseñables ${ }^{4}$. Nunca como entonces - hasta la VII Legislatura - se hicieron visibles los rasgos de concentración de poder que anteriormente hemos destacado: dominio del Poder Ejecutivo y de la dirección política, control de la labor legiferante de las Cortes e incluso control de la potestad de control de éstas sobre el Gobierno. El modelo descrito tenía cumplimiento casi al cien por cien.

El cuadro se repitió en la Legislatura siguiente, tras las elecciones de 1886, con algunos matices: el PSOE bajó en escaños, pero man-

4 Se escindió el PASOC, liderado por Alonso Puerta, tras su expulsión del PSOE, pero fue cuantitativamente poco significativo. 
tenía la mayoría absoluta. AP permanecía estancada en el $26 \%$ de los sufragios y el $30 \%$ de los escaños. Izquierda Unida, coalición integrada por el PC, el PASOC y personalidades y grupos independientes mejoró los resultados respecto de los del PC de las elecciones anteriores, alcanzando siete escaños. Creció mucho el Centro Democrático y Social (CDS), de Adolfo Suárez, que pasó de 2 a 19 escaños, lo que podía augurarle un futuro de partido bisagra.

El sistema de partidos parecía estabilizado, pero apuntando a un mayor pluralismo. A todo esto, el comportamiento de los partidos nacionalistas más fuertes (PNV y CiU) fue bastante estable en todas las elecciones habidas.

Así pues, aunque más ajustados, los resultados electorales permitian un ejercicio desahogado del poder (que siguió siendo hegemónico en las políticas municipal y autonómica), en tanto seguía inalterado el liderazgo interno del Presidente del Gobierno y Secretario General del PSOE.

En cambio, el panorama se manifestó parcialmente diferente en la IV Legislatura (1989-1993), cuyas elecciones de 1989 reflejaron, a mi juicio, algo sólo aparentemente contradictorio: estabilidad y cambio: el PSOE seguía perdiendo votos y escaños, pero se mantenía en el fiel del $50 \%$ de éstos. AP siguió en sus números habituales, pero con un nuevo líder, lo que hacia presagiar que su suelo era muy seguro y que su techo podía elevarse. IU siguió subiendo, hasta obtener 19 escaños. EI CDS declinó bastante, lo que ya se había puesto de relieve en las elecciones europeas anteriores $Y$, de los partidos nacionalistas, sólo cambió el voto vasco, pues, tras la escisión de Eusko Alkartasuna, se dividieron por mitades votos y escaños.

Habia, pues, elementos de estabilidad y de cambio. El partido gobernante pudo llevar adelante su programa sin agobios, para lo que no le faltaron apoyos (se los brindaron tantos los nacionalistas como el CDS, que acudieron oportunamente en socorro del vencedor), con lo que gobernaba casi como si tuviera una clara mayoría absoluta. Pero, como contrapartida, hubo más parlamentarismo, más presencia del Gobierno en las Cámaras. De otro lado, el CDS se vio ahogado por un socialismo y un conservadurismo cada vez más "centrados". E IU, a pesar de su incremento, no capitalizó, como esperaba, el enfrentamiento del Gobierno con los sindicatos.

Por lo que concierne a las otras condiciones (liderazgo interno en el partido gobernante y cohesión de éste), es cierto que se produjeron algunas grietas y tensiones, como la escisión de Democracia 
Socialista y la división interna de la Federación Socialista Madrileña en dos bloques mal avenidos. Pero su más grave problema residió en la confrontación, que duró varios años, con el sindicato socialista UGT y en la política de unidad de acción sindical acordada entre éste y Comisiones Obreras. En fin, la figura de Felipe González no sufría grave deterioro en el seno del Partido Socialista, pero se oían algunas críticas diluidas hacia su política.

También está siendo de pleno liderazgo la VII Legislatura, con todos los factores comentados a favor del Presidente del Gobierno y líder hasta hace un mes del Partido Popular (mayoría absoluta, partido muy cohesionado y líder indiscutido del mismo), hasta el punto de que ha sido la persona decisiva (acaso la única decisiva) a la hora de designar a su propio sucesor. Así como el liderazgo de Felipe González fue decreciendo poco a poco como efecto del desgaste experimentado por el ejercicio del poder, el de José María Aznar ha ido creciendo, $y$, dándose la circunstancia de su propia decisión de no prolongar su mandato, se ve con las manos muy libres para llevar su política a cabo, a veces en contra de la opinión de buena parte de su partido, que, no obstante, cierra filas en su defensa. En resumen, se ha tratado de un liderazgo pleno y creciente.

\subsection{Gobierno de liderazgo menos pleno ( $V$ y VI Legislaturas)}

Las Legislaturas $V$ y VI se parecieron entre sí a los efectos que estamos comentando, sólo que con intercambio de protagonistas: socialista en la $V$ y Popular en la VI. En ninguna de las dos obtuvieron mayoria absoluta los partidos ganadores de las elecciones (1993 y 1996), pero decidieron no formar Gobierno de coalición, sino gobernar en minoría, con apoyos puntuales -o firmes, según los casos - de los partidos nacionalistas (PNV, que se recuperó, CiU y Coalición Canaria). Todos ellos acordaron apoyar parlamentariamente al Gobierno, lo que se traducía lógicamente en su mayor protagonismo en la política nacional. Los condicionamientos de estos apoyos debilitaban la posición del Gobierno y, por ende, de su Presidente.

En efecto, durante la V Legislatura, el Presidente del Gobierno se vio precisado de pedir constantemente al líder de Convergencia i Uniò la confirmación de su apoyo, que era decisivo. Puede decirse que esta formación condicionó en alto grado la política de la legislatura, hasta el punto de pactar con el Gobierno los Presupuestos 
Generales del Estado. Finalmente, el Gobierno hubo de disolver las Cámaras y convocar nuevas elecciones, con sólo dos años y medio de legislatura, cuando dicha fuerza política votó en contra del proyecto de Ley de Presupuestos. El cambio político estaba a punto de consumarse.

De otro lado, el PSOE se agrietó más aún al compás de los acontecimientos, percibiéndose con toda nitidez un fuerte enfrentamiento entre dos sectores, seguidores respectivamente de sus dos líderes más significados. Lo que vale tanto como decir que el Presidente del Gobierno comenzaba a ser contestado en su propio partido, aunque no abiertamente. Aun así, el partido cerró filas en torno de él en las elecciones de 1996, en las que fue derrotado, pero evitó su derrumbamiento.

El Gobierno siguió respondiendo al modelo de liderazgo, pero ya de un liderazgo reducido, en función de las circunstancias comentadas, principalmente por CiU, que, si no gobernaba, tenía realmente capacidad de veto tanto respecto de personas cuanto de concretas acciones políticas.

El panorama comenzó de forma muy similar en la VI Legislatura, con un Gobierno con mayoría relativa, pero con un líder sólido, aunque no completamente afirmado. Las dependencias políticas eran las mismas de la legislatura anterior $y$, por tanto, damos por reproducidos anteriores comentarios. Pero, si bien su inicio fue casi idéntico, su decurso ha sido parcialmente diferente: el Partido Popular se cohesionaba progresivamente, lo que en muy buena parte fue obra de su líder y Presidente del Gobierno y éste incrementó notablemente su autoridad sobre el partido y sobre sus líderes históricos, algunos de los cuales fueron desapareciendo de la escena política.

Es decir, que aunque ambas legislaturas se corresponden a un modelo de liderazgo menos pleno por las razones apuntadas, el de la quinta fue decreciente, mientras que el de la sexta fue creciente (aunque continuó la «costumbre» de pactar los Presupuestos, así como la capacidad de "veto" antes mencionada) y se vio consolidado en la siguiente. De manera que el marasmo de la derecha de los años setenta y ochenta fue superado con notable éxito.

En conclusión, la falta de uno de los elementos de nuestra hipótesis de trabajo (la mayoria absoluta en el Congreso de los Diputados) no minó el Gobierno de liderazgo en ninguna de las dos legislaturas comentadas, aun con sus diferencias. 


\subsection{Gobierno de liderazgo decreciente (1979-1981)}

Hemos de retrotraernos ahora a la I Legislatura, cuyas elecciones iniciales arrojaron unos resultados similares que las de 1977, con un sistema de partidos que mostraba cambios mínimos. No obstante, tan sólo un mes más tarde, las elecciones municipales y las autonómicas del País Vasco y Cataluña de 1980 mostraron que un sistema de partidos algo más complejo. En realidad, era un sistema con tres subsistemas: el vasco, el catalán y el del resto de España.Y aún éste podría subdividirse en otros dos según miráramos la política general o la municipal. El poder, en conclusión, se hallaba más repartido que en la legislatura constituyente.

El Gobierno seguía con mayoría relativa y hubo de balancearse a un lado y a otro buscando apoyos puntuales para políticas concretas. El Gobierno y su Presidente dependían, por ende, de esos apoyos intermitentes. Así, por ejemplo, en 1979, el Partido Andalucista (por aquel entonces Partido Socialista de Andalucía) votó a favor de la investidura de Adolfo Suárez, pero en 1980 votó en contra suya y a favor de la moción de censura presentada por el PSOE en el Congreso. Otro ejemplo: el Partido Comunista, a veces, acordó medidas con el Gobierno de UCD buscando aislar al PSOE, pero votó igualmente a favor de la citada moción de censura.

De otro lado, el partido del Gobierno comenzó pronto a presentar fisuras. Nunca fue un partido propiamente dicho, sino una coalición de partidos de ideología dispar, aunque ubicados en el espacio de centro-derecha, y cada uno con su líder o líderes. Superado el periodo constituyente, dieron comienzo las desafecciones y la contestación interna frente al Presidente del Partido y del Gobierno, cuya figura, además, quedó dañada por la moción de censura de 1980 , varias veces citada.

Durante los dos años de "Gobierno Suárez" predominó todavía el liderazgo de éste, fundamentado en el prestigio alcanzado durante la transición política, pero era un liderazgo decreciente. El Gobierno no funcionó colegiadamente tampoco. Las crisis ministeriales se sucedieron vertiginosamente. EI grupo parlamentario sufrió el abandono de un amplio contingente de diputados, que pasaron al Grupo Mixto o al Popular. El Presidente del Gobierno no pudo siquiera disciplinar a su grupo parlamentario a la hora de elegir a su portavoz, revés sonado que puso de relieve el fin del liderazgo de Suárez. 


\subsection{Gobierno sin liderazgo (1981-1982)}

Dimitido Suárez, fue investido Calvo Sotelo, investidura azotada por un frustrado golpe de Estado, cuyos efectos se dejaron sentir durante el año y medio que restaba a la legislatura (marzo de 1981 a agosto de 1982).

Con un grupo parlamentario disminuido y sin la auctoritas de Suárez, el nuevo Presidente del Gobierno hubo de compartir el poder con el Presidente de UCD, el partido supuestamente sostenedor del Gobierno. Fue una experiencia de bicefalia que no dio el resultado pretendido, si es que se pretendía algo definido. El Gobierno no tenía mayoría absoluta (casi no tenía mayoría relativa, dados los abundantes abandonos sufridos por el grupo parlamentario), ni se apoyaba en un partido cohesionado, sino todo lo contrario, sumamente enrarecido, y el Presidente de aquél no era el líder del partido sustante, en el que ni siquiera tenía ningún predicamento. Es decir, faltaron los tres elementos en los que hemos cifrado el modelo de liderazgo.

En estas condiciones, no hubo liderazgo, ni Gobierno, ni partido gobernante, ni nada. Baste decir que, en ocasiones, el Gobierno logró sacar adelante una votación parlamentaria gracias a la abstención del grupo más importante de la Oposición, que buscó más el apuntalamiento de las instituciones en unos momentos sumamente delicados que su propio beneficio a corto plazo. Disueltas las Cortes, el Presidente del Gobierno ni siquiera pudo asegurarse su elección como diputado, ya que fue desplazado por su partido al segundo puesto de las candidatura de Madrid, resultando elegido solamente el primero.

\section{CONCLUSIÓN: LA COLEGIALIDAD COMO PRODUCTO DEL LIDERAZGO}

Creo que la hipótesis de trabajo acerca de los elementos en que se sostiene el modelo de Gobierno de fuerte liderazgo presidencial ha quedado verificada, aun con matices aquí y allá. En cambio, ha emergido una segunda conclusión inesperada; al menos, no descrita en la literatura jurídica. A saber: liderazgo y colegialidad no son dos modelos contrapuestos del Gobierno, sino mutuamente referenciales. La colegialidad es producto del liderazgo y está en relación directa con éste: a más liderazgo, más cohesión del Gobierno y mejor funcionamiento del conjunto; a menor liderazgo, más dispersión de los restantes miembros del Gobierno y, por tanto, menos entidad de éste 
como órgano colegiado; y a nulo liderazgo, práctica inexistencia del Gobierno, que queda en precario y a merced de cualquier viento político y de la mera inercia institucional.

Cuestión diferente es la que plantea el Gobierno de coalición, experiencia todavía inédita desde 1978 a nivel nacional. En este supuesto, no puede decirse que el programa del Gobierno sea el fijado por su Presidente, como tampoco su composición; ni es suya la decisión de presentar una cuestión de confianza, ni, finalmente, la de disolver la(s) Cámara(s), a despecho de lo dicho en el artículo 115.1 de la Constitución ("bajo su exclusiva responsabilidad»), pues en todo ello estará condicionado por las fuerzas políticas coligadas 5 .

Algo se asemeja a tal situación la de las legislaturas en que ha gobernado con apoyos parlamentarios (estables o puntuales), pero un Gobierno de coalición, al compārtir más explícitamente varias fuerzas políticas la responsabilidad de gobernar, también reparte entre ellas -o entre sus respectivos líderes- la dirección del conjunto.

\section{LIDERAZGO O COLEGIALIDAD DEL GOBIERNO DE LAS COMUNIDADES AUTÓNOMAS}

Perfil distinto presenta este problema del liderazgo gubernamental de las Comunidades Autónomas. Se discutió en un primer momento acerca de la calificación adecuada de los sistemas de Gobierno instaurados en éstas, si parlamentarios o presidenciales, o incluso si diferían de unas Comunidades a otras. Hoy parece haber remitido la polémica - que, ciertamente, nunca fue objeto de demasiada atención por parte de la doctrina - ante la evidencia de que la respuesta depende siempre más de los datos sociopolíticos, concretamente del sistema de partidos, que de la regulación estatutaria y/o legal de las relaciones entre los dos poderes clásicos: el Ejecutivo y el Legislativo.

Con todo, se puede apreciar alguna diferencia ocasionada por el dato jurídico en aquellas Comunidades en las que el Presidente puede ser automáticamente investido si el Parlamento no dirime la cuestión. Pues, en efecto, la confianza parlamentaria, por costosa que sea, une a dichos poderes en una suerte común, respaldando el Parlamento

5 Cfr. mi libro Principios de Derecho Constitucional Español, Servicio de Publicaciones de la Facultad de Derecho de la Universidad Complutense, 4." ed., Madrid, 1998, pág. 636. 
la política gubernamental en normalidad de circunstancias, en tanto que la investidura automática significa, de entrada, que no existe tal relación fiduciaria y que la Oposición, aunque no logre acordar un candidato alternativo a la Presidencia del Gobierno para incorporarlo a una moción de censura (o, previamente, para votarlo en la investidura), sin embargo, sí puede torpedear todas las iniciativas gubernamentales, dificultando hasta límites extremos - o incluso impidiendo - la gobernación de la Comunicad. Ejemplos ha habido ${ }^{6}$.

En estos supuestos apenas merece la pena plantearse la cuestión de si la dirección política responde al principio de liderazgo presidencial o al de colegialidad gubernamental, pues, en puridad, no hay ni lo uno ni lo otro. Pero en los demás casos, que son mayoría, bien por una regulación estatutaria más ortodoxa, bien por gozar un partido de mayoría absoluta, si cabe reflexionar sobre la disyuntiva enunciada.

En tales casos, y al igual que ocurre con el Gobierno nacional, la investidura la recibe el candidato a la Presidencia, no el Gobierno; los restantes miembros de éste son nombrados y cesados por el Presidente, de manera que deben a su entera discrecionalidad su acceso al puesto y su permanencia en él; y aunque suele repetirse en los estatutos que cada Consejero de Gobierno responde individualmente de su gestión, lo cierto es que la responsabilidad política es solidaria y se instrumenta en la Asamblea Legislativa, se llame ésta como se llame en cada Comunidad.

Esto último podría argüir a favor de la colegialidad, pero no resulta ser así porque los Consejeros de Gobierno dependen estrictamente de la confianza del Presidente. No hay ni puede haber solidaridad gubernamental antipresidencial, ni siquiera al margen del Presidente. Y, además, el propio Gobierno autonómico se solidariza ex statuto con el Presidente cuando la Asamblea exige la responsabilidad política de éste mediante una moción de censura y cuando es el propio Presidente el que plantea a la Asamblea una cuestión de confianza.

En estos apuntes se repite lo dicho para el Gobierno nacional. Como también sucede con los otros, los sociopolíticos, aunque con matices: el liderazgo presidencial se acentúan cuando el partido del

6 Cfr. Bar, A., "Comentario al artículo 22", en Bermejo Vera, J. (dir.), Comentarios al Estatuto de Autonomia de Aragón, Instituto de Estudios de Administración Local, Madrid, 1985, pág. 226. 
Gobierno goza de mayoría absoluta en el Parlamento, cuando está muy cohesionado y cuando el Presidente es líder indiscutido de dicho partido; $y$ desciende cuando falta alguno de dichos elementos, hasta disiparse por completo si faltan todos.

Los matices hay que ponerlos a la hora de evaluar la condición de liderazgo del Presidente del Gobierno autonómico respecto de su partido. Porque, de un lado, siempre tiene por encima la estructura nacional del mismo, lo que se acentúa si su partido es el que gobierna España, con lo que debe estar pendiente y ser obediente a las directrices nacionales de su partido; $y$, de otro, se da con alguna frecuencia la circunstancia de que el Presidente de la Comunidad es sostenido en su puesto por razones de partido y no po su propio predicamento social y político. Y por eso se han dado bastantes casos de que un Presidente autonómico, sin razón aparente ninguna, ha dimitido de su cargo o ha sido cambiado de puesto político porque así lo han decidido los intereses de su partido a nivel nacional.

Por lo demás, es obvio que el Presidente autonómico y su Gobierno no pueden separarse apenas del programa nacional de su partido, por lo que su política está claramente condicionada por este motivo. Ser líder regional del partido es mucho, pero no lo es todo. Y la situación baja aún muchos enteros cuando el Presidente autonómico ni siquiera es el líder del partido en su Comunidad, convirtiéndose más bien en un Presidente de conveniencia o meramente tolerado, el cual tiene una doble oposición: la de los partidos restantes de su Comunidad y la interna de su propio partido, que lo vigila estrechamente y lo sancionará, llegado el caso, con más efectividad incluso que la oposición tradicional.

En fin, damos por reproducidos los comentarios anteriormente hechos acerca de las dificultades de liderazgo cuando se gobierna con mayorías relativas y se tienen que buscar apoyos parlamentarios puntuales; o, más aún, cuando el Gobierno autonómico es de coalición. 